\title{
POPULISMO PUNITIVO Y COLAPSO CARCELARIO: HACIA UNA ABOLICIÓN GRADUAL DE LA PRISIÓN CERRADA EN COLOMBIA*
}

\section{Punitive Populism and Prison Collapse: Towards a Gradual Abolition of the Closed Prison in Colombia}

Juan Trujillo Cabrera**

Recepción: 23 de abril de 2017. Aceptación: 13 de junio de 2018.

DOI: http://dx.doi.org/10.21017/Rev.Repub.2018.v25.a53

\section{RESUMEN}

Este artículo explora las causas del populismo punitivo en Colombia y el consecuente colapso carcelario. Igualmente se consideran datos estadísticos con altas tasas de reincidencia delictiva, lo que permite llegar a la conclusión sobre el rotundo fracaso de la prisión cerrada, institución que tiene como principal función la de lograr la resocialización de los infractores. Como consecuencia, se propone replantear la utilización de la cárcel cerrada, con aplicación minimalista, esto es, solo para los casos que revistan mayor gravedad y se revisan algunas alternativas para la gradual abolición de este tipo de cárcel.

Palabras clave: Populismo Punitivo, Derecho Penal del Enemigo, sistema perverso, colapso carcelario, alternativas para la gradual abolición.

\begin{abstract}
This article explores the causes of punitive populism in Colombia along with its consequent prison collapse, which leads to propose the gradual abolition of closed prisons, as these institutions have failed to resocialize inmates. Taking into account collected data, it is found a need to rethink the use of closed prisons,
\end{abstract}

* Este artículo hace parte de la investigación denominada «Estudio de subrogados penales y mecanismos alternativos hacia una abolición progresiva del sistema carcelario», desarrollada dentro del Grupo de Investigación Derecho Laboral, Económico y Estado de la Corporación Universitaria Republicana, reconocido por Colciencias.

** Magíster Legum LL.M. de la Universidad de Osnabrück, Alemania. Abogado de la Universidad Externado de Colombia y docente investigador de la Corporación Universitaria Republicana. 
by using them minimally, in cases that are more serious. As a methodology of analysis, the article addresses four major aspects, such as Punitive Populism and the Criminal Law of the Enemy, the perversion of the closed prison system, the collapse of the closed prison in Colombia and finally, alternatives for the gradual abolition of closed prisons.

Key words: Punitive populism, the criminal law of the enemy, perverse system, prison collapse, alternatives for gradual abolition.

\section{PROBLEMA DE LA INVESTIGACIÓN}

En caso de concluirse la inviabilidad del sistema carcelario cerrado en la función resocializadora del infractor, ¿qué alternativas pueden contemplarse para la gradual abolición de este tipo de cárcel?

\section{POPULISMO PUNITIVO Y DERECHO PENAL DEL ENEMIGO}

\section{El Populismo Punitivo como herramienta política para encarcelar más personas}

Existe consenso entre los expertos de que al hacinamiento carcelario se llega, entre otros factores, por el populismo punitivo. El populismo punitivo es la práctica de promover el encarcelamiento en masa y penas más crueles, con apoyo electoral, utilizando para ello la manipulación de los medios de comunicación y el estímulo de las emociones más primitivas.

Se atribuye a Anthony Bootoms haber acuñado el término populismo punitivo, para referirse al uso del Derecho Penal que realizan los gobernantes con el fin de obtener ganancias electorales, "asumiendo política y acríticamente que el agravamien to e incremento de las penas reducirán el delito y salvaguardarán el consenso moral existente en la sociedad» (Antón-Mellón, Álvarez, y Rothstein, 2017, p. 7).

Según Juan Antón-Mellón, el fenómeno del populismo punitivo nace unido a lo que David Garland denomina el surgimiento de la nueva «cultura del control». «Según este autor, «en las décadas posteriores a la Segunda Guerra Mundial, la respuesta estándar a los problemas relacionados con la delincuencia, y a la mayoría de los problemas sociales, era una combinación de trabajo social, reforma social, tratamiento profesional y recursos sociales». No obstante, desde la década de los ochenta, se ha producido un cambio de paradigma y de modelo, pasando de criterios resocializadores a incapacitadores. De ahí que, para este autor, mediante el término populismo punitivo designamos la forma en que los expertos han dejado de controlar las formas de encarar la criminalidad, substituidos por una óptica en ex- 
tremo politizada de la cuestión penal» (Antón-Mellón, Álvarez, y Rothstein, 2017, p. 8).

Estos autores -fundamentados igualmente en los trabajos de L. Wacquant, Tory, Rutherford y Bussmann, entre otros- vienen sosteniendo que el populismo punitivo irrumpió en las sociedades industrializadas en las décadas de los $70 \mathrm{y}$ 80 del siglo XX, en el contexto histórico del neo-liberalismo, como una forma de gobernar a través del delito, esto es, solucionar los problemas sociales a través de la criminalización (Antón-Mellón, Álvarez, y Rothstein, 2017, p. 9).

Algunos instrumentos empleados en el ejercicio del Populismo Punitivo, son:

\section{a) La explotación del miedo}

Sobre la explotación del miedo en la población por parte de los demagogos, con el fin de repletar las cárceles, Hawkins y Zimming sostienen que incrementar el miedo de la sociedad es una técnica obvia para lograr que los ciudadanos le permitan voluntariamente a un gobierno reducir sus propias libertades. "Y esto genera un motivo fuerte para que los gobiernos que buscan poder adicional exageren el peligro del delito y de los criminales. La tarea política es convencer a los ciudadanos que la criminalidad es una amenaza mayor que el exceso gubernamental» (Reed Hurtado, 2014, p. 21). De esta forma el llamado es al pánico social, como maquiavélico mecanismo para que el pueblo ceda en sus derechos y fortalezca el poder del demagogo.

Según Garland, bajo el ropaje del pánico y la angustia de la población civil frente a la criminalidad, el Derecho Penal y el castigo se convierten en los motores de un proceso moralista que subyuga a la sociedad frente a la clase gobernante, permitiéndole ofrecer la solución total a un mundo lleno de riesgos (Reed Hurtado, 2014, p. 21).

La revolución de la televisión transformó la psiquis de la población, las relaciones sociales y el sistema de poder. Hoy el consumidor compulsivo de Televisión vive enamorado con el discurso que promete más castigo. Su estado de hipnosis lo sumerge en la venganza, porque así es como los medios le han ensuciado su mente. El mal llamado «Lavado de Cerebro» consiste en dividir a la población en dos bandos: los televidentes, que son los buenos y por otra parte, los que salen en el Televisor, que son los malos. Como el Homo Televidente quiere ver presos a los posibles delincuentes que ve y escucha todos los días en el televisor, cae en la trampa de solicitar más castigo y mayor venganza. Pero lo que ignora el televidente vengador, es que los figurines de esa pantalla negra raramente pisarán una cárcel. No importa si se trata de políticos corruptos, tecnócratas saqueadores del erario público, o incluso terroristas. Nunca irán a 
una cárcel. Casi siempre el peso de la ley recaerá sobre el televidente-ciudadano a la primera oportunidad que brinde.

Es por esto que Reed Hurtado señala que la irreflexión y el permanente estado de inseguridad dominan la política criminal (Reed Hurtado, 2014, p. 21).

\section{b) La maquiavélica estrategia de «Problema-Reacción-Solución»}

Una de las técnicas más empleadas en el Punitivismo, es la denominada «Problema-Reacción-Solución».

Explica el penalista Eugenio Raúl Zaffaroni, que el interesado en implementar las leyes que limitan las libertades civiles de su propio pueblo, anuncia en los medios que el Problema es que la sociedad se encuentra inundada de criminalidad. En dicho ejercicio repite a diario mantras como «tolerancia cero», "guerra», «mano dura», «inseguridad» o similares. Este anuncio genera una Reacción social de miedo, rabia e indignación. La idea es que el cerebro reaccione ante el supuesto problema con sensación de peligro; de esta manera el sistema límbico activa el instinto de supervivencia. Bajo ese estado de stress y alteración hormonal crónica, la alborotada turba le exige al Gobierno que imponga medidas urgentes y más drásticas que sacrifiquen su propia libertad. Es así como las autoridades recogen el clamor popular para brindar la Solución, que los afectados estarán abiertos y deseosos de recibir.

También Icke sostiene que la película que vemos y oímos a diario en los noticieros, solo tiene la función de presentar -muchas veces- falsas explicaciones para los eventos masivos, que ocultan el verdadero significado y sus motivos. Señala que la gran mayoría de periodistas son tan ignorantes como cualquier otra persona; incluso, muchas veces lo son todavía más (Icke, 2012, p. 210).

Otro método para introducir medidas punitivas es el «No Problema-Solución», es decir, cuando se implementa la restricción a las libertades sin que el público lo perciba. Funciona cuando se aprueba una disposición normativa a la que no se le hace mayor difusión o que está disfrazada u ocultada. Su aplicación se realizará de manera gradual, de forma que la población se vaya acostumbrando a ella sin mayor discusión o debate.

\section{c) La función de los jueces es contener el ejercicio del poder punitivo}

Nada ha cambiado del pollice verse (con el pulgar al revés) con el que la plebe romana suplicaba en el coliseo el golpe de gracia, a la actual justicia touch del smarthphone. Es posible que la mayoría de comunicadores no sean conscientes del rol que desempeñan en este círculo vicioso. Aunque en la Era 
del sensacionalismo muchos buscan amplificar el pánico para aumentar su rating, se lanzan al aire soluciones punitivas cada vez más gravosas, ignorando que serán víctimas de su propio invento. Es así como Zaffaroni sostiene que la función de los jueces es contener el ejercicio del poder punitivo, en vez de acentuarlo. Por esta razón también es normal ver a los abogados penalistas corrigiendo con frecuencia al periodismo.

De acuerdo con el criminólogo David Garland, en mayor o menor medida todas las corrientes políticas gobiernan con el Código Penal. En nuestra región se ha convertido en moda proponer consultas populares sobre temas punitivos. Incluso se ha llegado al extremo de la aglomeración de muchedumbres movilizadas en marchas, clamando por penas más severas o intentando persuadir a la magistratura sobre el sentido de alguna providencia judicial. Todo ello contribuye a la degeneración del sistema en una Demagogia.

\section{d) Actuales intenciones legislativas que reflejan el ascenso de la Demagogia Punitiva en Colombia}

En Colombia nos encontramos bajo la mayor oleada de Populismo Punitivo que se recuerde y proviene de distintos sectores. Entre otras medidas urgentes, hoy nos anuncian:

1. Imprescriptibilidad de todos los delitos contra la Administración Pública. Se olvida que los términos de prescripción son la garantía a ser juzgado en un Plazo Razonable.

2. Cadena perpetua para abusadores y violadores sexuales. Se omite que una de las funciones de la pena es la Reinserción Social.

3. Reducción de la edad de imputabilidad de menores. Se desconoce que los niños no pueden ser tratados igual que los adultos, siendo el Derecho Penal la Última Razón.

4. Cárcel para evasores. Se pasa por alto el aforismo de No hay cárcel por deudas.

5. Reincidencia como circunstancia de mayor punibilidad. Castigar con mayor severidad a los reincidentes, implica Sancionar dos veces la misma conducta.

6. Aumento de penas. Se ha demostrado en el mundo que el aumento de penas No disuade la comisión de delitos.

7. Consulta Anticorrupción. Preguntarle al pueblo, si está de acuerdo o no con que se investigue y sancione a los corruptos, se cae de su propio peso. 
8. Redacción de un nuevo Código Penal. Implica revisar nuevamente principios rectores, teoría del delito, responsabilidad civil del punible y más de 400 tipos penales.

9. Redacción de un nuevo Código de Procedimiento Penal. Un procedimiento diferente al del sistema acusatorio, agravaría el traumatismo de la actual Coexistencia de sistemas procesales.

10. Eliminación de la Corte Suprema de Justicia. Algunos insisten en eliminar la Corte Suprema de Justicia, donde se adelantan procesos contra altas dignidades del Estado.

Sin duda que la implementación de estas propuestas, incrementará el número de sospechosos detenidos y con ello, las tasas de hacinamiento carcelario.

\section{El Derecho Penal del Enemigo}

Luego de analizar la teoría política y la doctrina jurídico penal dominante a lo largo de la historia, Zaffaroni sostiene que en Latinoamérica se han impuesto las corrientes que defienden que el poder punitivo discrimine a seres humanos y les depare un trato no correspondiente a la condición de personas, reduciéndolos solo a entes peligrosos o dañinos (Zaffaroni, 2006, p. 19-21). Se trata de seres humanos a los que se señala como enemigos de la sociedad y, por ende, se les niega el derecho a ser sancionados dentro de los límites del Derecho Penal liberal ${ }^{1}$, esto es, el garantista que hoy establece el derecho internacional de los Derechos Humanos ${ }^{2}$.

1 Para el liberalismo (Locke y Feuerbach) solo hay infractores o delincuentes (iguales). Según Zaffaroni, la función de la política liberal es garantizar la paz entre los ciudadanos (todos iguales) sancionando a los infractores según la gravedad de la infracción. A los súbditos les surge el derecho a la resistencia, cuando el soberano actúa contra la sociedad civil y por ende, viola el contrato. Por tanto, el liberalismo reconoce y acepta unos derechos naturales previos a la existencia del contrato social. En cambio, para el absolutismo (Hobbes, Kant y Schmitt), además de los infractores (iguales) hay enemigos de guerra (extraños), que son aquellos que no aceptan voluntariamente el contrato. La función de la política absolutista es además de garantizar la paz entre los ciudadanos (iguales), neutralizar a los enemigos (extraños) con la guerra y así la sanción a los infractores pasaría a ser una cuestión menor. El Estado siempre tiene enemigos (extraños) que le hacen la guerra y la sanción a los infractores pasaría a ser una cuestión menor. El absolutismo no admite el derecho a la resistencia, por cuanto que los que se resisten son precisamente los enemigos (extraños) (Zaffaroni, 2006, p 181).

2 Declaración Universal de Derechos Humanos, art. 3 (recurso de rebelión contra la tiranía y la opresión), art. 18 (derecho de resistencia y derecho de protesta implícitos en la libertad de pensamiento, de conciencia y de religión), art. 19 (libertad de opinión y de expresión) y art. 20 (libertad de reunión y de asociación pacífica). 
Para Zaffaroni la característica más predominante del poder punitivo latinoamericano actual, en su carácter prisionizante, es que la gran mayoría (3/4 partes) de los presos se hallan sometidos a medidas de aseguramiento, lo que significa que no se les ha demostrado aún su responsabilidad penal. Esto constituye una inversión del sistema penal, por cuanto se priva la libertad por presunción de peligrosidad (Zaffaroni, 2006, p. 90-91).

En América Latina los disidentes son tolerados en mayor medida, aunque aumenta la represión a la protesta social de los excluidos del sistema productivo, mediante la aplicación extensiva de tipos penales. Los iguales son cada vez más reducidos por la profundización de la desigualdad y el inequitativo reparto de la riqueza (Zaffaroni, 2006, p. 91-92).

\section{El Estado Policiaco}

El funcionamiento del Estado está diseñado para que una vez sean proferidas las leyes que endurecen las penas, el poder punitivo quede en manos de los agentes administrativos. Incluso, muchas veces el poder punitivo se desplaza directamente al Derecho Administrativo. Entonces, el populismo punitivo también tiene una forma de expresarse, que es a través del Estado Policiaco.

El Estado Policiaco es el que, bajo la excusa de proteger a la sociedad de algún enemigo, se ensaña administrativamente en disciplinar la conducta individual y moral de los ciudadanos.

A esta descomposición se llega cuando se adoptan medidas que le permiten a los agentes administrativos inmiscuirse en la vida íntima de los ciudadanos. Expertos consideran que el Estado Policiaco es la antesala al Autoritarismo Cool, un régimen marcial dirigido por civiles, pero disfrazado con una sobrecarga de entretenimiento y farándula.

En el Estado de Policía el poder punitivo se administrativiza. Así, para eludir el control constitucional de los jueces penales, la coerción se realiza sagazmente desde el Derecho Administrativo. Esta situación se percibe cuando los enemigos son definidos principalmente por las agencias administrativas, esto es, por los Ministerios, departamentos administrativos y superintendencias. Pero finalmente son los policiales administrativos los que retienen temporalmente al ciudadano y así, van creando una estadística. Este volumen de información lo ingresan al Big Data, que comparten con las demás agencias, empresas y bancos. Una vez es reseñado en el sistema, el ciudadano ya nunca volverá a salir de esa caja negra (Icke, 2012, p. 210).

Es preocupante cómo los síntomas de un Estado Policiaco empiezan a percibirse en Colombia. Las alarmas se encendieron cuando el Estado adoptó decisiones 
dirigidas a minimizar el daño cometido por sus acciones arbitrarias. Se ha buscado es restringir la indemnización por detenciones carcelarias. El Consejo de Estado, máxima autoridad en lo contencioso administrativo, ha limitado la indemnización a personas injustamente privadas de la libertad. Esto aumentará inevitablemente el número de detenciones arbitrarias ${ }^{3}$.

\section{La cárcel cerrada}

Actualmente quienes cometen delitos en Colombia se enfrentan a un sistema penitenciario cerrado, lo que significa que deben estar confinados ya sea en cárceles cerradas o en sus hogares bajo el sustituto de la detención o prisión domiciliaria.

Las alternativas a la prisión que ofrecen el Código Penal y el de Procedimiento (multas, conmutación de la pena, medidas de aseguramiento no carcelarias), son poco usadas por los jueces, por distintos factores que a continuación serán analizados, lo que se traduce en encarcelamientos masivos y hacinamiento en prisiones, de forma selectiva.

\section{Factores socio-políticos para el alto nivel del encarcelamiento}

Se estima que a finales del año 2010 se encontraban más de 10 millones de personas recluidas en prisiones de más de 200 países (Pérez, 2015, p.141) ${ }^{4}$. En

3 Entre otras peligrosas iniciativas para consolidar un Estado Policiaco en Colombia, está la de crear una Super-procuraduría. El nuevo órgano -altamente politizado- tendría agentes encubiertos y facultades para realizar extinciones de dominio. Verdaderamente crítico para el ejercicio del derecho de defensa, es la nueva disposición de criminalizar a los abogados defensores. Los penalistas pagarían una pena de prisión de 6 a 10 años, cuando defiendan a "grupos delictivos» sin que hayan podido demostrar el origen lícito de sus honorarios. En este proceso de selección del enemigo, desde agencias administrativas se ha empezado a estigmatizar a las personas tatuadas, como individuos «drogadictos y libertinos». Otro enemigo puede resultar de la creación del Ministerio de Familia. Esta agencia formularía acciones judiciales en defensa de la familia, lo que puede convertirse en una verdadera persecución en contra de aquellos que ideológica y fanáticamente, sean etiquetados como «agresores de la familia». También ha resultado controversial el decreto que persigue al consumidor de dosis mínima de droga, sometiéndolo a un engorroso proceso verbal ante agentes de policía. Por último y para calmar los ánimos de cualquier indignado, existe la intención de reglamentar la protesta social. Se quiere que una Ley expresamente señale, qué protestas en contra de la Administración se permiten. Obviamente las que no se ajusten a estos parámetros, serían objeto de una buena reprimenda policial.

4 Pérez Toro señala que, considerando que para el año 2000 había 8’707.428 personas detenidas en prisiones, se tiene que para finales de la década se presentó un incremento del $16 \%$. Estas cifras podrían dispararse aún más, ya que no se cuenta con datos de Afganistán, Irak, Laos, Sierra Leona y Corea del Norte, entre otros. 
solo Sudamérica la población carcelaria para 2012 era de cerca de un millón de personas, de los cuales 114.284 estaban recluidas en prisiones colombianas.

Si se le compara con los Estados Unidos, se observa con preocupación que mientras que en dicho país la población intramural creció en la última década un $41 \%$, en Colombia el aumento fue del 242\% (Pérez, 2015, p.144) ${ }^{5}$.

Como fenómeno global que es el aumento del encarcelamiento masivo, AntónMellón, Álvarez y Rothstein -siguiendo la clasificación realizada por Larruariidentifican cuatro aspectos que han determinado las altas tasas de encarcelamiento en las sociedades occidentales (Antón-Mellón, Álvarez, y Rothstein, 2017, p. 5):

1. El neoliberalismo económico. El advenimiento del Estado neo-liberal acrecienta la desigualdad y la pobreza, lo que a su vez desencadena en inseguridad laboral y emigración de las empresas. En este contexto, el grupo que entra a engrosar a la clase pobre terminan siendo las minorías étnicas y los tradicionalmente excluidos.

2. El neoconservadurismo político. Esta corriente política deshumaniza al infractor de la ley penal respecto de las causas personales y sociales que lo impulsan a cometer el acto, y lo reducen a un simple ser racional responsable de sus acciones.

3. La amplificación del estado de inseguridad ciudadana. Los medios de comunicación influyen poderosamente en la generación y amplificación del miedo, creando una sensación permanente de inseguridad.

4. El aumento continuado del delito. A medida que se crean más tipos penales, aumenta el número de delincuentes.

6. La selectividad del sistema carcelario en contra de los más pobres

En las sociedades latinoamericanas -señala Zaffaroni- el principal problema lo constituye la exclusión social. El mensaje vindicativo es funcional para reproducir conflictos entre excluidos, pues a este segmento pertenecen los criminalizados, los victimizados y los policizados. La polarización de la riqueza que provocó el neo-liberalismo (la economía globalizada) deterioró gravemente a las clases medias. Pareciera que a medida que la riqueza se polariza, la sociedad pierde cohesión y el discurso se vuelve primitivo, vindicativo, populachero y simplista, que clama simple venganza (Zaffaroni, 2006, p. 94).

5 Según la Revista Newsweek, edición del 23 de febrero de 2015, la mitad de la población carcelaria del mundo se encuentra en los EEUU, Rusia y China. 
En la región se introduce el discurso vindicativo, vendiendo la ilusión de que se obtendrá mayor seguridad urbana contra el delito común, sancionando sin mesura a los más vulnerables y marginados (a menudo son débiles mentales) y aumentando la arbitrariedad policial (Zaffaroni, 2006, p. 98).

\section{LA PERVERSIÓN DEL SISTEMA CARCELARIO CERRADO}

\section{La ignominia de la cárcel}

Vale la pena compartir las reflexiones de Gloria María Gallego García sobre las ideas y creencias morales acerca del castigo carcelario.

Sostiene que la cárcel (cerrada) es una ignominia contra la humanidad, ya que el recluso penetra en un universo alineante en el cual su vida está organizada y dispuesta por otros y toda relación está reglada por la absoluta obediencia, por la fuerza y por temor a cosas peores (Gallego García, 2015, p. 107).

Desde el comienzo -señala Gallego- los internos tienen que sufrir toda clase de degradaciones y profanaciones de su propio ser, relacionados con su identificación en el interior del centro de reclusión, la guarda de sus objetos personales, desinfección y corte de pelo, así como toda cantidad de registros. Ello significa la imposición de una mortificación psicológica, lo que deteriora su identidad y autoestima: dormir en celdas colectivas (generalmente bajo hacinamiento), baños sin puertas y con deficiencias de servicios públicos y total pérdida de la identidad. Igualmente hay un inevitable proceso de mortificación física generado por el confinamiento entre muros, con privación de espacio, luz y aire. A ello se suman alimentos mal preparados y desbalanceados, que deterioran considerablemente el organismo del individuo (Gallego García, 2015, p. 106-110).

Difícil no estar de acuerdo con Gallego, en que la cárcel cerrada constituye un atentado permanente contra la humanidad, por su carácter degradante al despreciar al ser humano. Es por esta razón -concluye-, que cárcel y humanidad se repelen y excluyen mutuamente. Doscientos años de institución carcelaria han demostrado su fracaso y por tanto, parece haber llegado el momento de dejar de legitimarla (Gallego García, 2015, p. 135).

\section{La banalidad del Mal}

Quien acuñó el término la banalidad del mal fue Hannah Arendt, con la publicación en 1963 de su libro Eichmann en Jerusalén: un estudio sobre la banalidad del mal. La investigación de Arendt se centró en el comportamiento, respuestas y 
análisis realizados por el líder nazi Adolf Eichmann, durante su juicio por crímenes de guerra.

Considerando que los campos de concentración eran cárceles y que allí se gestaron toda clase de violaciones a los derechos humanos hasta desatarse en un holocausto, resulta interesante revisar la descripción que hace Arendt de Eichmann, responsable directo de la solución final, principalmente en Polonia, y de los transportes de deportados a los campos de concentración

Respecto del examen médico a Eichmann, seis psiquiatras certificaron que se trataba de un hombre normal. Alguno de los profesionales valoró que su actitud hacia su esposa, sus hijos, su padre y su madre, sus hermanos, hermanas y amigos, era no solo normal, sino ejemplar (Arendt, 1999, p. 25-26).

Así es como Arendt llega a la conclusión de que lo más grave, en el caso de Eichmann, era que hubo muchos hombres como él y que no fueron pervertidos ni sádicos, sino «terroríficamente normales». Señala que desde el punto de vista de las instituciones jurídicas y morales occidentales, dicha normalidad resultaba más terrorífica que todas las atrocidades juntas, porque implicaba que este nuevo tipo de delincuente comete sus delitos en circunstancias que casi le impiden saber que los realiza con maldad (Arendt, 2015, p. 276) ${ }^{6}$.

Por eso la expresión banalidad del mal, que refleja cómo las fuerzas sociales, jurídicas y políticas pueden hacer que personas normales cometan actos horrendos ${ }^{7}$.

\section{La psicopatización de los guardias y del personal administrativo en las cárceles cerradas}

En diferentes universidades de prestigio mundial se han realizado experimentos sicológicos en el ambiente de las prisiones. El más famoso, el Experimento de la Cárcel de Stanford, ha sido repetido en otras universidades con resultados similares, los cuales concluyen que en el sistema de prisión cerrado se

6 Arendt, Hannah. Eichmann en Jerusalén. Penguin Random House Grupo Editorial, Barcelona, 1999, p. 276.

7 Explica Arendt que la llamada Solución Final «fue seguida por un diluvio de reglamentos y ordenanzas, documentos todos redactados por expertos juristas y no por funcionarios administrativos» y que «...la orden de Hitler, a diferencia de las ordenes corrientes, recibió el tratamiento propio de una ley. No es necesario añadir que los consecuentes formalismos jurídicos, lejos de ser una simple manifestación de pedantería o perfeccionamiento alemán, cumplieron muy eficazmente la función externa de dar apariencia de legalidad a la situación existente». (Arendt, 1999, p. 219). 
producen causas que pueden degenerar fácilmente en sadismo por parte de los funcionarios encargados de custodiar y operar las cárceles.

\section{a) La transformación del comportamiento por un simple cambio de rol}

En 1971 se hizo célebre el sicólogo Philiph Zimbardo, de la Universidad de Stanford, California, con una investigación que pretendía demostrar, cómo el entorno y el ambiente pueden modificar la conducta y el carácter de los individuos. A pesar de que el estudio se realizó dentro de los sótanos de la propia universidad, la investigación se conoció como «El experimento de la cárcel de Stanford» (Zimbardo, 2012, p. 140).

Relata Zimbardo en su libro «El efecto Lucifer» ${ }^{8}$, que él creía que no era habitual que a una persona se le pidiera que hiciera algo malo, ya que vivimos en instituciones, familias, escuelas, hospitales, ejército y policía, donde se le asigna al individuo unas reglas, un rol y un trabajo dentro del marco de la legalidad. En ese entorno la persona empieza a hacer cosas que quizás no encajen con su moral, pero simplemente las continúa realizando porque el resto de los miembros de la institución también las hace

En el estudio se buscaron estudiantes voluntarios, que aceptaron participar durante varias semanas en una simulación sobre la vida en la cárcel. Luego se hicieron test de personalidad y entrevistas, y se seleccionaron a 25 individuos blancos, que correspondían a los perfiles psicológicos más estables y al mejor comportamiento social.

8 Zimbardo explica el título de su libro «El efecto Lucifer». Para el efecto, alude a «la transformación suprema del bien en el mal, la metamorfosis de Lucifer en Satanás. Lucifer, el «portador de luz», era el ángel favorito de Dios hasta que se enfrentó a la autoridad divina y fue arrojado al infierno junto con los otros ángeles caídos. «Mejor es reinar en el infierno que servir en el cielo», se jacta Satanás, el «adversario de Dios» en El paraíso perdido de Milton. En el infierno, Lucifer-Satanás se convierte en un embustero, en un vanidoso impostor que alardea con lanzas, trompetas y estandartes, como los dirigentes de muchos países de hoy. En el congreso demoníaco que reúne a los principales demonios del infierno, se le dice a Satanás que no podrá recuperar el cielo mediante una confrontación directa. Sin embargo, al príncipe de Satanás, Belcebú, se le ocurre la más malvada de las soluciones para vengarse de Dios: corromper su creación suprema, el género humano. Aunque Satanás tiene éxito al tentar a Adán y Eva para que desobedezcan a Dios y caigan en el mal, Dios decreta que, al final, el ser humano se salvará. Sin embargo, hasta que llegue ese momento, Satanás tiene libertad para reclutar a brujos y brujas para con su ayuda tentar a la humanidad y hacerla caer en el mal. Más adelante, estos intermediarios de Satanás se convertirían en el blanco de los fervientes inquisidores que deseaban librar al mundo del mal, aunque sus métodos horrendos acabarían dando origen a una nueva forma de maldad sistémica que el mundo, hasta entonces, no había conocido» (Zimbardo, 2012, p. 24). 
Lanzando una moneda al aire, se eligieron al azar a los reclusos y a los carceleros. Para hacerlo más convincente, Zimbardo se encargó de que la policía de Stanford detuviera a los estudiantes que iban a desempeñar el rol de reclusos y los arrestaran conforme a la ritualidad. Los esposaron, los subieron a la patrulla y los llevaron a la comisaría, en donde les tomaron huellas dactilares y fotografías (Zimbardo, 2012, p. 71).

En seguida los policías les vendaron los ojos y Zimbardo -que desempeñaba el rol de director de la prisión-, los trasladó en un vehículo hasta la cárcel ficticia.

El grupo que se desempeñaría como guardias había llegado un día antes a la cárcel, con el fin de que se familiarizaran con el lugar y desarrollaran sentido de pertenencia por la institución. Les asignaron uniformes, silbatos, esposas y gafas de sol reflectivas, para que nadie pudiera verles los ojos (Zimbardo, 2012, p. 75) ${ }^{9}$.

Todos los participantes sabían que se trataba de una simple simulación. Los guardias eran buenas personas, muchos eran hippies y activistas de los derechos civiles.

Sin embargo, al cabo de dos días los guardias empezaron a decir que los reclusos eran peligrosos y que tenían que aplacarlos. La razón fue que, al segundo día, los presos se rebelaron y dijeron que no querían llevar números, ni gorras en la cabeza y empezaron a insultar a los guardias. Para preservar el orden, los guardias utilizaron la fuerza física contra los reclusos. En ese momento el experimento se transformó en una cárcel real ${ }^{10}$.

Si bien Zimbardo había prohibido el empleo de violencia, durante los siguientes días los guardias recurrieron también a la agresión sicológica. En los turnos en que los presos estaban fuera de sus celdas, los guardias aprovechaban la oportunidad para abusar de ellos.

Lo peor ocurría en la noche porque los guardias sabían que Zimbardo iba a dormirse. Al día siguiente, aquel miraba el video y observaba las graves humillaciones que habían recibido los reclusos.

9 Durante el primer día, tanto los reclusos como los guardias se sentían desplazados del rol que tenían que cumplir, puesto que de alguna forma rechazaban los «papeles» que se les habían asignado.

10 Al segundo día, los guardias ya habían empezado a ver cómo se difuminaba la línea que separaba su propia identidad y del rol que debían cumplir. 
Zimbardo, como director de la cárcel, se limitaba a llevar un control rutinario de la situación, un simple observador, sin sentir ningún remordimiento ni arrepentimiento. Sin embargo, el experimento terminó abruptamente al sexto día mucho antes de lo proyectado-, cuando Zimbardo fue visitado por su novia, quien se horrorizó con el sadismo que estaba ocurriendo en los sótanos del Departamento de Psicología. Zimbardo, con su pasividad, también había caído en lo más bajo de su propia naturaleza.

Basándose en otro trabajo similar, el experimento de Milgram ${ }^{11}$, Zimbardo concluyó que los sujetos uniformados (y mejor, si podían ocultar de alguna manera su rostro o identidad), eran capaces de ser más agresivos y sádicos, que si iban con ropa de calle (Levy, 2013, p. 65).

Según Zimbardo, las conductas asociadas a las instituciones penitenciarias no tienen que ver con el carácter individual, sino que es la propia institución la que parece influir en el comportamiento, al dictar los roles de sus miembros (Levy, 2013, p. 65).

El experimento se repitió en Australia con el mismo resultado: la maldad fue consecuencia del diseño carcelario y no de los rasgos de las personas.

\section{b) Universos paralelos: Stanford y la cárcel La Modelo de Bogotá}

Más allá de las críticas recibidas al experimento de Stanford (Haslam, y Reicher, 2004, 94), entre ellas la de Eric Fromm, al cuestionar la metodología de aislamiento utilizada a un pequeño grupo de la población (Fromm, 1998, 86) ${ }^{12}$; el experimento sigue siendo un modelo comparable con lo que ocurre en el escenario real.

Un ejemplo lo constituye el caso de la Cárcel La Modelo de Bogotá. Solo hasta el año 2016 se destapó la olla podrida de lo que ha venido ocurriendo en esta prisión. Y es que, según las autoridades, entre febrero de 1999 y mayo del

11 Este experimento fue llevado a cabo por el psicólogo social Stanley Milgram, en New Haven (Conneticut) en la década de 1960. Sus resultados dieron a entender que cualquier persona común y corriente era capaz de infligir descargas eléctricas dolorosas e incluso letales, simplemente por cumplir órdenes. La investigación causó sensación y fue el antecedente del Experimento de la Cárcel de Stanford (Levy, 2013, p. 66).

12 Respecto de la destructividad por simple placer, Fromm sostiene que esa manifestación se produce cuando no media ninguna situación en que corra riesgo la vida de quién asume una conducta cargada de agresividad. Fromm estableció que existía una relación entre la destructividad y el amor a la vida, y así lo dijo: «... el impulso de vida y el de destrucción no son factores mutuamente independientes, sino que son inversamente proporcionales». 
2000, dentro de la cárcel se cometieron graves violaciones a los derechos humanos por desaparición y asesinato de varias personas ${ }^{13}$, entre reclusos, visitantes, abogados y personas ajenas al penal, cuyos restos fueron arrojados por la red de alcantarillado. Según revista Semana, estas desapariciones también habrían ocurrido en las prisiones de Barranquilla, Bucaramanga y Popayán.

Según declaraciones rendidas por los diferentes directores del INPEC, así como por guardias de la época, «jamás tuvieron conocimiento de lo ocurrido» 14.

No deja de asombrar el paralelismo entre el experimento de Stanford y los graves hechos ocurridos en las cárceles colombianas, particularmente en La Modelo, donde una nómina inmensa de funcionarios públicos, que va desde los dragoneantes hasta los directores, nunca vieron ni escucharon nada fuera de lo normal. Y esta escalera de poder institucional asciende a autoridades de policía, funcionarios del INPEC, auxiliares y ministros ${ }^{15}$. Asombra igualmente la pasividad de la Fiscalía en la investigación del caso (Foucault, 2013, p. 77).

13 La Comisión Interamericana de Derechos Humanos (CIDH) expresó su preocupación ante la información divulgada por la Fiscalía de Colombia, sobre la presunta desaparición y descuartizamiento de al menos 100 personas entre los años 1999 y 2001 en la cárcel La Modelo, ubicada en Bogotá. La CIDH señaló que espera que la investigación que adelanta la Fiscalía continúe su curso con debida diligencia hasta esclarecer todo lo ocurrido, de manera que la justicia pueda establecer responsabilidades y sancionar a los responsables. Estas investigaciones no sólo deben estar orientadas a establecer los responsables materiales de los hechos, sino también a los posibles autores intelectuales y a aquellas autoridades que podrían ser responsables por acción u omisión. Asimismo, la CIDH urge al Estado de Colombia que adopte todas las medidas necesarias para prevenir la repetición de hechos similares, en particular la implementación de acciones para adecuar las condiciones de detención de la cárcel La Modelo y otros centros de reclusión a los estándares internaciones y para garantizar la vida y la integridad de las personas privadas de libertad. El Estado debe, como medidas fundamentales, garantizar y mantener la seguridad interna de los centros penales y controlar el ingreso de armas y de sustancias ilícitas, así como la circulación de dinero dentro de las cárceles. Además, debe buscar mecanismos para reducir el hacinamiento y la superpoblación en las cárceles. CORTE INTERAMERICANA DE DERECHOS HUMANOS, Comunicado de prensa del 25 de febrero de 2016, http://www.oas.org/es/cidh/prensa/comunicados/2016/020.asp.

14 El general Jorge Luis Ramírez, director del INPEC, manifestó el 18 de febrero de 2016, que «no tenía información sobre descuartizamiento de personas en la cárcel La Modelo de Bogotá». «Llevo quince meses al frente del INPEC y no tenía información sobre descuartizamiento de personas». Periódico El País, de Cali, edición del 18 de febrero de 2016.

15 De acuerdo con un testimonio, postulado de Justicia y Paz, las más de cien desapariciones ocurridas entre 1998 y 2001 en la cárcel La Modelo de Bogotá eran conocidas por el Instituto Nacional Penitenciario y Carcelario (INPEC). Véase TELESUR, Gobierno colombiano sabía de las desapariciones en la Cárcel La Modelo, edición escrita del 22 de febrero de 2016. 
En consecuencia, los funcionarios parecen seguir una especie de «guion psicológico", que es completamente ajeno al sentido común. En tal medida, pareciera que el experimento concluye que una persona con uniforme ${ }^{16}$, en un rol de autoridad, se vuelve fácilmente propensa a convertirse en un sádico (Levy, 2013, p. 65).

Se cree que la alta burocratización facilita la deshumanización (despojar a los otros de cualidad humana), la desindividualización (vestir traje o máscara de autoridad), la obediencia ciega al poder (acatar órdenes aberrantes) y la autojustificación (autoconvencerse de algo que se sabe que es errado).

\section{c) ¿Cómo explica la neurociencia el sadismo en las cárceles?}

Un informe reciente del Massachusetts Institut of Technology (MIT), concluye que cuando las personas se reúnen en grupos, se generan comportamientos que una persona no realizaría por sí sola. Dicha pertenencia a un grupo, hace a las personas más propensas a dañar a otros fuera del grupo ${ }^{17}$. Según Rebecca Saxe, profesora asociada de neurociencia cognitiva en el MIT, las prioridades de las personas cambian cuando hay un «nosotros» y un «ellos». Varios factores juegan en esta transformación. Cuando las personas están en un grupo, se sienten más anónimas y con menos probabilidades de ser atrapadas haciendo algo mal. También pueden sentir una disminución del sentido de la responsabilidad personal por las acciones colectivas ${ }^{18}$. Saxe y sus colegas estudiaron recientemente un tercer factor que los científicos cognitivos creen que pueden estar implicados en este grupo dinámico: la hipótesis de que cuando las personas están en grupos,

16 Interesante cómo ese «uniforme» no necesariamente debe ser el de un policía, un soldado o un dragoneante. En los Estados Unidos existe un fuerte debate, desde que el 2 de Julio de 2015, se hizo público un documento elaborado por la APA (American Psychological Association), en el que se denuncia la participación de la APA en técnicas e interrogatorios nacionales de seguridad y tortura. El documento completo se encuentra en: http://www. apa.org/independent-review/APA-FINAL-Report-7.2.15.pdf. Se trata de la denuncia de cómo psicólogos profesionales asesoraron e instruyeron a interrogadores y supervisores con el fin de «ablandar» a los prisioneros en el complejo carcelario de Guantánamo (Cuba), los calabozos de Abu Ghraib (Irak) y la base aérea de Bagram (Afganistán). Literalmente, durante un tiempo prolongado, cientos y miles de prisioneros detenidos fueron sometidos a interrogatorios y torturas con todas las técnicas y sofisticaciones de algunos de los más avezados psicólogos en el mundo.Fuente: Pacarina del Sur - http:// www.pacarinadelsur.com/home/saberes-y-horizontes/1265-psicologia-ciencias-del-comportamiento-y-neurociencias-un-estudio-cientifico-y-politico

17 Massachusetts Institut Of Technology (MIT). MIT News on campus and around the world. Informe del 12 de junio de 2014, publicado en versión electrónica en http:/ / news.mit.edu / 2014/when-good-people-do-bad-things-0612.

18 MIT. MIT News on campus and around the world. Informe del 12 de junio de $2014 \ldots$ 
«pierden contacto» con sus propias costumbres y creencias, y se vuelven más propensas a hacer cosas que normalmente creerían que están mal ${ }^{19}$.

En un estudio que se puso en línea en la revista NeuroImage, los investigadores midieron la actividad cerebral en una parte del cerebro involucrada en la reflexión sobre uno mismo ${ }^{20}$. Encontraron que, en algunas personas, esta actividad se redujo cuando los sujetos participaron en un concurso como parte de un grupo, en comparación a cuando compitieron como individuos. Esas personas eran más propensas a dañar a sus competidores que las personas que no presentaban esta disminución de la actividad cerebral ${ }^{21}$.

Por su parte, un estudio realizado por investigadores de las universidades de Duke y Princeton, afirma que estos comportamientos de sadismo se vinculan con un fallo en la red neuronal implicada en la interacción social y en el reconocimiento de otras personas como «humanos» ${ }^{22}$. Con la activación de las emociones de disgusto o rechazo, la red puede desconectarse, generando que dichas personas deshumanicen a otros individuos y olviden que estos tienen pensamientos y sentimientos humanos. En el comunicado de la Universidad de Duke, se afirma que «cuando nos encontramos con otra persona, normalmente deducimos algo sobre sus pensamientos. Pero, a veces, esta función cognitiva falla, lo que abre la posibilidad a que no percibamos al otro como completamente humano» ${ }^{23}$.

\section{EL COLAPSO DE LA CÁRCEL CERRADA EN COLOMBIA}

\section{El estado de cosas inconstitucional en materia carcelaria en Colombia}

Desde 1998 la Corte Constitucional colombiana declaró el estado de cosas inconstitucional por el hacinamiento que se vive en las cárceles del país. Esta posición

19 MIT. MIT News on campus and around the world. Informe del 12 de junio de $2014 \ldots$

20 De acuerdo con el informe del MIT, se estudió lo que sucede en el cerebro de los individuos cuando están en un grupo. Midieron en concreto la actividad neuronal en una parte del cerebro involucrada en la reflexión sobre uno mismo: la corteza prefrontal medial. Descubrieron que dicha actividad se redujo cuando los voluntarios participaron en un juego como parte de un grupo, en comparación con cuando compitieron como individuos. Esas personas presentaron además más probabilidades de dañar a sus competidores que las que no presentaban esa disminución de la actividad cerebral.

21 MIT. MIT News on campus and around the world. Informe del 12 de junio de $2014 \ldots$

22 Universidad de Duke. A Brain's Failure to Appreciate Others May Permit Human Atrocities. Duke Today. Informe del 14 de diciembre de 2011, publicado en versión electrónica en http:/ / today.duke.edu/2011/12/dehumanize.

23 Universidad de Duke. A Brain's Failure... 
fue reiterada en el año 2013, luego de verificar que ha empeorado la situación de hacinamiento y las condiciones de salud de los reclusos. Las decisiones de la Corte han quedado plasmadas en las sentencias T-153 de 1998 y T-388 de 2013, y reiterado a través de la sentencia T-025 de 2015. En esta última, la Corte señaló:

«(i) la vulneración masiva y generalizada de varios derechos constitucionales que afecta a un número significativo de personas; (ii) la prolongada omisión de las autoridades en el cumplimiento de sus obligaciones para garantizar los derechos; (ii) (SIC) la adopción de prácticas inconstitucionales, como la incorporación de la acción de tutela como parte del procedimiento para garantizar el derecho conculcado; (iii) la no expedición de medidas legislativas, administrativas o presupuestales necesarias para evitar la vulneración de los derechos. (iv) la existencia de un problema social cuya solución compromete la intervención de varias entidades, requiere la adopción de un conjunto complejo y coordinado de acciones y exige un nivel de recursos que demanda un esfuerzo presupuestal adicional importante; (v) si todas las personas afectadas por el mismo problema acudieran a la acción de tutela para obtener la protección de sus derechos, se produciría una mayor congestión judicial».

Aún no se ha diseñado un nuevo modelo penitenciario, ni de descongestión de prisiones, más allá de la Ley 1760 de 2015, que busca modificar los criterios para aplicar las medidas de aseguramiento, con el argumento de que la privación de la libertad debería ser la excepción del sistema penal, lo extraordinario, y no la regla.

Si bien el Código Penal (art. 4) dispone que la pena cumple las funciones de prevención general, retribución justa, prevención especial, reinserción social y protección al condenado; lo cierto es que el estado de cosas inconstitucional en materia carcelaria, declarado desde hace 20 años, con el decidido abandono del Estado por la situación de los establecimientos penitenciarios y de los reclusos; demuestra que las penas y medidas de aseguramiento se siguen aplicando con un criterio vindicativo y estigmatizador. Ni se está tratando con un mínimo de dignidad a los reclusos, ni mucho menos, se está cumpliendo con el objetivo principal de la pena, que es la de resocializar al individuo.

El modelo carcelario colombiano ha conducido a la situación infrahumana en la que actualmente viven miles de reclusos. 
Las prisiones del país muestran cifras escandalosas de hacinamiento y violación a los derechos humanos ${ }^{24}$. Además, las instalaciones e infraestructura no solo se encuentran en pésimo estado, sino que, en varios casos carecen de servicios públicos básicos. De esta manera no se está cumpliendo con la principal función de la pena, que es la resocialización. Por el contrario, se está castigando brutalmente a individuos, en el interior de una verdadera fábrica de crímenes y resentimientos.

A ello se le suma el conocido proceso de degradación del individuo desde que ingresa a la prisión, que es sometido a una serie de "profanaciones del yo", que van desde el reemplazo de su nombre por un número, hasta someterse a desinfecciones, cortes de pelo y en general, a una pérdida casi absoluta de su identidad y sus derechos.

Aunque la Corte reconoce la existencia de una situación que requiere de intervenciones de carácter estructural, se abstiene de declarar libertades o de cerrar establecimientos de manera inmediata.

La solución que siempre se plantea por parte de los políticos de turno a esta problemática, es construir más cárceles. No obstante, la construcción de nuevos penales lo único que hará es acrecentar el problema, puesto que le estará dando vida a un ciclo vicioso y corrupto, dominado por la oferta y la demanda de cupos carcelarios, lo que puede estimular el incremento de más detenciones y mayor número de reclusos ${ }^{25}$.

24 En el desarrollo del convenio de cooperación firmando entre la Oficina en Colombia del Alto Comisionado de las Naciones Unidas para los Derechos Humanos y la Defensoría del Pueblo, se concluyó que el hacinamiento carcelario «...Trae como consecuencia graves problemas de salud, de violencia, de indisciplina, de carencia en la prestación de servicios (trabajo, educación, asistencia social, deportes, educación, visita conyugal, servicios médicos, etc.), con una clara violación de la integridad física y mental de los reclusos, de su autoestima y de la dignidad humana. Igualmente, el hacinamiento, cuando sobrepasa el nivel crítico, se convierte en una forma de pena cruel, inhumana y degradante. Para la comisión es claro que en los penales que presentan condiciones de hacinamiento crítico, la calidad de vida de los reclusos sufre serios deterioros, al punto que no se pueden considerar sitios seguros ni para los internos, ni para el personal que trabaja con ellos. «En síntesis, a mayor hacinamiento, la calidad de vida de los reclusos y la garantía de sus Derechos Humanos y fundamentales es menor». Fuente: INPEC. Informe estadístico enero. Oficina Asesora de Planeación. Edición No. 01 de 2014.

25 Sobre las cifras de hacinamiento carcelario en Colombia, véase Arenas, L. \& Cerezo, A. (2016). Realidad penitenciaria en Colombia: la necesidad de una nueva política criminal. Revista Criminalidad, 58 (2): 175-195. 


\section{ALTERNATIVAS PARA LA GRADUAL ABOLICIÓN DE LA CÁRCEL CERRADA}

\section{La propuesta del G-DIP de la Universidad de los Andes}

Muy interesante es la propuesta presentada por parte del Grupo de Derecho de Interés Público (G-DIP) de la Universidad de los Andes, para transformar el sistema penitenciario colombiano.

Lo que plantea el G-DIP, es reubicar a los reclusos en alguno de los nuevos cuatro sistemas que se crearían, de acuerdo al perfil socioeconómico, naturaleza y gravedad de los delitos, entre otros factores ${ }^{26}$. El punto de partida es reconocer que la mayor parte de los reclusos actuales, ocupan el segmento de población altamente vulnerable y necesitada, razón por la cual la prisión cerrada casi nunca es la mejor vía para solucionar el problema.

\section{a) Cárceles abiertas y semiabiertas:}

Este modelo estaría concebido para personas que hayan cometido delitos de bajo impacto, tales como el hurto simple o que sea la primera vez que hayan delinquido. Lo que se busca es que estas personas puedan demostrar que sus condiciones socioeconómicas los llevaron a cometer la falta.

Señala la propuesta que el régimen consistiría en que, de lunes a viernes, los infractores cumplirían con las labores designadas por el Estado durante el día y fuera de las instalaciones de la prisión, para resarcir a la comunidad y deberán volver a las cárceles, de baja y media seguridad, en las noches y durante los fines de semana ${ }^{27}$.

Incluso los reincidentes y que se encuentren en el régimen semiabierto, tendrían la posibilidad de pasar algunos fines de semana en sus casas con sus familias bajo supervisión del Estado. El proceso se complementaría con jornadas

26 Ver https://www.cej.org.co/seguimientoreforma/index.php/noticias-en-medioscodigo/217-estudio-propone-cuatro-regimenes-carcelarios-distintos

27 Sostiene Carlos Mir Puig, que «La prisión abierta constituye una alternativa a la prisión clásica; es un reto a la misma: Ante el fracaso resocializador de las cárceles de máxima seguridad, en las que es prácticamente imposible ensenar a vivir en libertad, apartando totalmente al interno de la sociedad, se alza la prisión abierta como una institución resocializadora, que aplica un tratamiento en condiciones de semilibertad; es una nueva modalidad de prisión, un nuevo planteamiento de la ejecución de la pena privativa de libertad. La prisión abierta nace con la aceptación de forma generalizada de la resocialización como criterio ordenador de la ejecución penal. En la prisión abierta no caben otros criterios: ni de expiación, ni retributivos, ni vengativos» (Mir Puig, 1985, p. 3). 
de estudio y aprendizaje, lo que le permitiría al infractor integrarse de manera efectiva a la sociedad al terminar su pena ${ }^{28}$.

En realidad la propuesta del G-DIP está inspirada en gran medida en el sistema escandinavo de prisiones, que incluso permite que los reclusos vivan en un entorno ecológico y puedan salir libremente a la ciudad, para realizar actividades de resocialización, como educarse en la universidad o trabajar, y regresar en el horario o fecha establecidos, según los compromisos asumidos ${ }^{29}$. Modelos de cárceles abiertas y semiabiertas escandinavas

1. La prisión de Halden Fengsel en Noruega: Fue concebida desde su diseño arquitectónico, como centro de rehabilitación, gracias a que el estilo responde al tipo "prisión-pueblo», consistente en cuatro edificios habitacionales ubicados dentro de un área boscosa. A pesar de ser considerada por las autoridades locales como prisión de máxima seguridad, no hay dispositivos de seguridad convencionales, como el alambre de púas, cerca eléctrica, torres de vigilancia ni francotiradores. La prisión de Halden Fengsel tiene un horario diario amplio (de 8 am a las 8 pm) en régimen de semi libertad, con autorización para la práctica del trote por los senderos y del deporte. De igual manera se ejerce la carpintería, la cocina y se dictan clases de música. En el estudio musical, los internos también tienen la oportunidad de grabar música y realizar un programa mensual difundido por la estación radial de la localidad.

A pesar de que el sistema carcelario de Halden Fengsel está basado en un «enfoque humano», ha sido blanco de críticas y muchos lo consideran demasiado blando. Sin embargo, es difícil argumentar que no funciona, ya que la reincidencia criminal en Noruega es del $20 \%$, una de las tasas más baja del mundo ${ }^{30}$.

2. La Isla ecológica de Bastoy: Es una prisión de mínima seguridad en Noruega. Está organizada como una pequeña comunidad local. Los reclusos tienen solamente dos obligaciones: permanecer en su 'casa' a partir de las 11 de la noche y trabajar en el campo, el taller o el barco de pesca de 8.30 de la mañana hasta las 14.30, hora en que se sirve la comida.

28 Ver https://www.cej.org.co/seguimientoreforma/index.php/noticias-en-medioscodigo/217-estudio-propone-cuatro-regimenes-carcelarios-distintos

29 Tomado del diario argentino Clarín, se cita un reportaje de Warrian Hoge, En Finlandia, las prisiones no tienen barrotes ni guardias armados, publicado originalmente en New York Times y traducido al español el 6 de febrero de 2003.

30 Tomado de la revista Time. Adams, William. Noruega construye la prisión más humana del mundo. Artículo publicado el 10 de mayo de 2010. 
La prisión y el conjunto de la comunidad de la isla se desempeñan bajo los valores y la comunión con la ecología. Esto significa que la agricultura es ecológica, generando sistemas reciclables de eliminación de basuras, buscando siempre la minimización de las emisiones de dióxido de carbono (Pratt, 2007, p. 86).

Interesante cómo los valores de la comunidad de la isla de Bastoy, se centran en el compromiso ecológico, lo que según las autoridades ha permitido que florezca las relaciones entre las personas y su entorno social. Con esto, se espera que todos los miembros se centren en las relaciones humanas y el cuidado de la naturaleza (Pratt, 2007, p. 86).

3. La Granja de Kerava en Finlandia: Es una finca agrícola abierta, sin puertas, muros ni rejas. Se trata de una granja con capacidad para 70 presos, cuyo oficio es trabajar diariamente en el invernadero. Los reclusos perciben remuneración por hora laborada y pueden comunicarse permanentemente con sus familiares y amigos, puesto que tienen celulares. Igualmente, se les permite salir a hacer compras a la ciudad y disfrutar de tres días de vacaciones por cada dos meses de prisión. Algunos reclusos prefieren optar por estudiar una carrera universitaria en la ciudad en vez de trabajar, por lo que reciben un subsidio (Bichell, 2015, p. 2).

El flexible modelo penitenciario finlandés ha permitido que el Estado se ahorre grandes sumas en construcción y mantenimiento de cárceles y que la tasa de delincuencia se reduzca a niveles muy bajos.

\section{b) Cárceles semicerradas y cerradas:}

A diferencia de los sistemas semiabierto y abierto, en los que el interno necesitaba ayuda de la sociedad para resarcirse y reintegrarse; el G-DIP propone que las cárceles semicerradas estén concebidas para que el recluso sea quien colabore con el Estado. Tratándose de delitos de alto impacto social (secuestros, extorsiones, estafas y concierto para delinquir, entre otros), el recluso estaría en prisiones de alta y máxima seguridad, pero con la posibilidad de recibir mayor número de visitas a la semana, lo que le permitiría motivarse para adelantar procesos de redención de pena por medio de estudio y trabajo ${ }^{31}$.

31 Ver https://www.cej.org.co/seguimientoreforma/index.php/noticias-en-medioscodigo/217-estudio-propone-cuatro-regimenes-carcelarios-distintos 
En cambio, la cárcel cerrada se limitaría únicamente para los autores y partícipes de crímenes atroces, que permanecerían en las prisiones todo el tiempo de la condena y solo podrían recibir una visita a la semana, tal como sucede hoy en día ${ }^{32}$.

Lo mejor de esta propuesta es que el viejo esquema de la cárcel cerrada tendría un uso minimalista, únicamente para las personas que no pueden tener contacto con la sociedad por la gravedad de los crímenes cometidos.

Modelos de cárceles cerradas en Europa

1. El Centro de Justicia Leoben, en Austria: Tiene una moderna arquitectura enfocada en hacer que las celdas aparenten ser un apartamento común y corriente de la ciudad, minimizando la seguridad y la sensación de encierro. Investigaciones en Austria han demostrado que el diseño interior de la cárcel de Leoben, tiene un efecto positivo en el clima general de la prisión, entre los reclusos y entre los mismos supervisores. Los alojamientos hacen una diferencia significativa en el bienestar de los internos, lo que contribuye al mantenimiento de un ambiente relajado, lo que a su vez se refleja en un factor de seguridad importante (Lewis, 2009, p. 5).

2. La prisión de Addiewell en Escocia: Está diseñada como un centro de enseñanza, donde los presos abordan directamente su comportamiento infractor y las circunstancias que los llevaron a su encarcelamiento. El aprendizaje tiene como objetivo mejorar sus perspectivas de empleabilidad, sus redes de bienestar y apoyo a la comunidad, lo que lleva a una reducción de la reincidencia. Las actividades se dividen en tres áreas principales: Desarrollo de habilidades, trabajos e intervenciones programadas ${ }^{33}$.

2. Otras medidas no privativas de la libertad aún no contempladas en la legislación colombiana

\section{a) Los arrestos de fin de semana}

Sería la modalidad más flexible de la cárcel abierta, ya que se le permitiría al infractor ser productivo laboral o en el ámbito educativo durante los días hábiles de la semana, viviendo en su hogar e integrado a la sociedad.

32 Ver https://www.cej.org.co/seguimientoreforma/index.php/noticias-en-medioscodigo/217-estudio-propone-cuatro-regimenes-carcelarios-distintos

33 Información oficial de las autoridades de la Prisión de Addiewell. http:// www.sps.gov.uk/Corporate/Prisons/Addiewell/HMP-Addiewell.aspx 
Ha sido utilizado en Alemania, Canadá, Francia e Inglaterra, frente a delitos de bajo impacto o accidentes de tránsito que alcanzan la categoría de delitos (Flores, 2016, p. 137-138).

\section{b) El trabajo obligatorio en libertad}

Consiste en la obligación del condenado de trabajar en determinados lugares (por lo general a servicio del Estado), lo que le permite al infractor liberarse del yugo de la prisión. Parte del sueldo puede ser utilizado para reparar a las víctimas (Flores, 2016, p. 137-138).

\section{c) Servicio en provecho de la comunidad}

Se trata de trabajos no remunerados en beneficio de la comunidad. Debe ser una pena aceptada por el condenado, con el fin de desterrar cualquier idea referente a «trabajos forzados».

El trabajo debe ser asignado y facilitado por la administración pública, no puede atentar contra la dignidad del infractor y aunque no sea remunerado, si debería ser compensado con los beneficios de la seguridad social. Las jornadas no pueden sobrepasar las 8 horas diarias.

\section{CONCLUSIONES}

1. Como factores socio-políticos que han influido en elevadas tasas de encarcelamiento a nivel global, se encuentran el neoliberalismo económico, el neoconservadurismo político, la amplificación del estado de inseguridad ciudadana y el aumento continuado del delito.

2. La degeneración de la democracia en Populismo Punitivo ha llevado a altas tasas de encarcelamiento. Para lograrlo, los populistas se han valido de la explotación del miedo y la denominada estrategia «ProblemaReacción-Solución».

3. En Colombia nos encontramos bajo la mayor oleada de Populismo Punitivo que se recuerde, la cual aumentará las tasas de encarcelamiento.

4. Se observa en Colombia cada vez más acentuado el ascenso de un Estado Policiaco, que bajo la excusa de proteger a la sociedad de algún enemigo, se ensaña administrativamente en disciplinar la conducta individual y moral de los ciudadanos. A esta descomposición se llega 
cuando se adoptan medidas que le permiten a los agentes administrativos inmiscuirse en la vida íntima de los ciudadanos.

5. En Colombia, como en el resto de América Latina, existe selectividad del sistema carcelario contra los más pobres. Se introduce el discurso vindicativo, vendiendo la ilusión de que se obtendrá mayor seguridad urbana contra el delito común, sancionando sin mesura a los más vulnerables y marginados.

6. Se ha demostrado en el mundo, con varios experimentos en aclamadas facultades de Psicología, que el sistema carcelario cerrado está diseñado para perturbar las psiquis de los guardias y del personal administrativo.

7. Desde hace 20 años la Corte Constitucional colombiana ha declarado el estado de cosas inconstitucional, sin que hasta el día de hoy se haya superado dicho vejamen a los derechos fundamentales de miles de reclusos.

8. Como alternativas a la abolición gradual de la cárcel cerrada, se destaca la propuesta del G-DIP, al dividir el sistema penitenciario en cuatro grandes categorías: cárceles abiertas, semiabiertas, cerradas y semicerradas.

9. Interesante sería la utilización de la cárcel cerrada solo para los casos más graves.

10. Otras medidas no privativas, aún no contempladas en la legislación colombiana, pueden ser los arrestos de fin de semana, el trabajo obligatorio en libertad y el servicio en provecho de la comunidad.

\section{REFERENCIAS}

Antón-Mellón, Juan; Alvarez, Gemma y Rothstein, Pedro. (Marzo de 2017). El populismo punitivo en España (1995-2015): presión mediática y reformas legislativas. Revista Española de Ciencia Política. Asociación Española de Ciencia Política y de Administración, No. 43.

Arendt, Hannah. (1999). Eichmann en Jerusalén. Barcelona. Penguin Random House Grupo Editorial.

Bichell, Rae Ellen. En las 'cárceles abiertas' de Finlandia, los presos tienen las llaves. Artículo publicado el 15 de abril de 2015, en PRI. Puede consultarse versión electrónica en español en https:/ / es.globalvoices.org/2015/04/21/en-las-carcelesabiertas-de-finlandia-los-presos-tienen-las-llaves/ 
Foucault, Michel. (2013). El poder, una bestia magnífica. Sobre el poder, la prisión y la vida. Buenos Aires. Siglo Veintiuno Editores.

Flores Muquis, Joselito. (2016). Cárcel abierta en América Latina. Bogotá. Editorial Leyer.

Fromm, Erich. (1998). Anatomía de la destructividad humana. Madrid. Siglo XXI de España.

Gallego García, Gloria María. (2015). Humanidad e Inhumanidad. La ignominia de la cárcel. En ¿Reformar o abolir el sistema penal? Bogotá, Siglo del Hombre Editores.

Haslam, Alexander; y Reicher, Stephen. (2004). Visión crítica de la explicación de la tiranía basada en los roles: pensando más allá del Experimento de la cárcel de Stanford. España. Univertity od Exter; University of St Andrews. Revista de Psicología Social, Vo. 19, p. 94.

HOGE, Warrian. En Finlandia, las prisiones no tienen barrotes ni guardias armados, publicado en New York Times y traducido al español por el diario argentino Clarín el 6 de febrero de 2003.

Levy, José. (2013). Experimento de Milgram, en Lapsus freudianos. Barcelona. Editorial Océano.

Icke, David. (2012). El despertar del león. Barcelona. Ediciones Obelisco.

Lewis, Jim. Una prisión de la que nadie quiere escapar. Artículo publicado en septiembre de 2009, para New York Times Magazine. Versión electrónica puede consultarse en http://www.elboomeran.com/upload/ficheros/noticias/inquilinos.pdf

Mir Puig, Carlos. (1985). La prisión abierta. Madrid. Anuario de Derecho Penal y Ciencias Penales, Ministerio de Justicia, Tomo 38, Número 3.

Pratt, John. (2007). Excepcionalismo escandinavo en una era de exceso penal. Artículo publicado en 2007 por Oxford University Press y el Centre for Crime and Justice Studies,

Perez Toro, William. (2015) ¿Más Prisiones?, en ¿Reformar o abolir el sistema penal? Bogotá. Siglo del Hombre Editores.

Reed Hurtado, Michael. (2014) ¿Y quién dijo miedo? Un estado de necesidad fabricado para gobernar mediante el crimen. En Delito y tratamiento penitenciario en el contexto de los derechos humanos. Medellín. Universidad Autónoma y Latinoamericana UNAULA.

Zaffaroni, Eugenio Raúl. (2006). El Enemigo en el Derecho Penal. Bogotá. Librería Ibáñez.

Zimbardo, Philip. (2012). El efecto Lucifer. El porqué de la maldad. Madrid. Ediciones Paidós. 